\title{
Didactical reflections on the teaching and training of mathematical modeling course at local colleges
}

\author{
Qingyun Zou ${ }^{a}$, Xuyan Xiang ${ }^{b}$, Renwei Jia ${ }^{c}$ and An Yuan ${ }^{d}$ \\ Department of Mathematics, Hunan University of Arts and Science, Changde, Hunan 415000, \\ P.R.China. \\ a qyzou2000@sina.com, b 179059961@qq.com, ${ }^{\text {c } 283163306 @ q q . c o m, ~}{ }^{d} 2607202338$ @qq.com
}

Keywords: Curriculum design, Mathematical Experiments, Mathematical software, Problemsolving, Mathematical Modeling.

\begin{abstract}
During the last ten years mathematic education in China focuses on promoting students to develop their mathematic modeling competences. In this paper, we want to concentrate on the problem in traditional mathematical modeling course. We give a brief introduction to the current status of the course in China, and shares our experiences in teaching and training of the course at Hunan University of Arts and Science, in which the course tries to integrate the problem-solving methods such as mathematical modeling and mathematical software. Moreover, we state several suggestions on the teaching and training of mathematical modeling course.
\end{abstract}

\section{Introduction}

Supported by Ministry of Education of China, a project entitled "Reforms on the Course System and Teaching Content of Higher Mathematics (For Non-Mathematical Specialties)” commenced in China starting from 1995. Several years later, the research report of the project was released [1,2], which has been producing profound impacts on the understanding of the role of university mathematics education, and has been significantly changing the situation of mathematics education in Chinese universities. How to stimulate the students' interest in learning mathematics, how to cultivate the students' innovation ability and Mathematical literacy, which are all university mathematics educators to think and explore. Modeling problems are only one kind of reality related tasks. Since there is a large variety of reality related tasks we will have a look at a classification of these problems at first. While modeling is a real world problem, we move between reality and mathematics. By simplifying, structuring and idealizing this problem, you get a real model. The mathematizing of the real model leads to a mathematical model. By working within mathematics a mathematical solution can be found. This solution has to be interpreted first and then validated. If the solution or the chosen process does not prove to be appropriate to reality, particular steps or maybe even the entire modeling process need to be worked through again.

China Undergraduate Mathematical Contest in Modeling (CUMCM) was rapid development in resent years, which founded in 1992, and listed by Ministry of Education of China as one of the four major contests of [3] university in 1994. In 2012, 21219 teams from 1284 colleges and universities in China and other countries, and more than 63600 students participate in the competition. In the past five years, the examination questions of CUMCM were close to our life such as Chinese population growth forecast (2007), evaluation of the students' dormitory design (2010) and Analysis of heavy metals contamination in urban topsoil; Setting and scheduling of traffic and patrol police service platform; Pension policy revolution for enterprise retirees (2011), if we gave an optimal solution, it would produce huge social effect and economic benefit. Mathematical models are being extensively used in very many different scientific and technological disciplines and in many societal contexts. In this perspective, mathematical modeling is viewed as applied problem solving and a strong emphasis is put on the real life situation to be modeled and on the interdisciplinary approaches[7].

\section{Current status of mathematical modeling course in China}

Many universities in China start to offer mathematical modeling course to undergraduates, thus, there have been active researches into the course design and teaching reform. Related to the 
educational perspective, the goal is developing the students' mathematical modeling competency. Mathematical modeling bridges the gab between students' real life experiences and mathematics. It motivates the students' learning of mathematics, gives direct cognitive support for the students' conceptions, and it places mathematics in the culture as a means for describing and understanding real life situations. To solve many problems such as engineering and technical, financial management and economic construction and so on, mathematical modeling plays a crucial role[4,5,6,8]. The course not only emphasizes the need for students to learn applied mathematics (in particular, numerical computing, optimization and statistics) by doing mathematics themselves, but also focuses on cultivating the students' mathematical application consciousness and ability. The advantage of studying mathematical modeling course: (a) cultivation innovative consciousness and creative ability; (b) improvement the ability of quickly understanding and mastering new knowledge and skills; (c) cultivation the team cooperation spirit; (d) improvement computer application ability and writing technology paper ability. In order to facilitate the teaching and training, they have established their laboratories for mathematical modeling.

\section{Existing problems in the teaching mathematical modeling course:}

- Currently in China, the mathematical knowledge selected for the course in this form is more mathematics-oriented, and is probably more suitable to the students who like to become a mathematician in the future, but perhaps it does not fit all the students, especially the students not majoring in mathematics. The traditional mathematical courses in China are usually theoretically oriented and taught by introducing modeling cases, but computer and mathematical software are not often used. Different understandings exist on the issues related to what kind of mathematics should be taught in the course, and what kind of pedagogies should be accepted for the course.

- The lack of well-qualified staff and support of the university.

- Some university presidents too care about the results of CUMCM, and deviate from the direction of the course.

Many teachers consider that modeling activity is hard to implement in mathematics classroom, however, these kinds of activities can promote students' problem-solving and mathematics thinking. In addition, teachers feel modeling-activity will be helpful to improve traditional instruction and this kind of instruction is worthy to attempt in the future.

\section{Mathematical modeling course at Hunan University of Arts and Science}

Our research has the double focus characteristic for the educational perspective. On the one hand, mathematical modeling is seen as a means to challenge and develop the students' mathematical understanding and especially their basic mathematical beliefs. On the other hand, mathematical modeling is seen as an educational goal in its own right.

Hunan University of Arts and Science, a local college, do well in CUMCM. In the past three years, we have won the four second prize of CUMCM and provincial first prize 5, and so on, and have finished education of project of provincial educational reform, education to study positive result 5. In our university, the most serious problem in mathematics education is that mathematics is considered just as a tool subject in which theoretical mathematics focusing on mathematical knowledge is emphasized more than practical mathematics focusing on its utility. The emphasis on the examination without internal motivation for learning has made it difficult for students to have real understanding and to develop reasonable and productive thinking abilities. As a result, it becomes almost impossible for students to nurture an investigative attitude and a desirable mental habit. The ultimate goal of mathematical modeling in our university is to cultivate students with a creative and autonomous mind by achieving the following three main aims: First, to understand basic mathematical concepts and principles through the concrete experiences with various manipulative materials and the use of daily life phenomena related with mathematics; second, to foster mathematical modeling abilities through solving various problems posed within mathematics; Third, to keep a positive attitude about mathematics and mathematics learning 
through emphasizing a connection between mathematics and the real world. How to stimulate students interest in learning, how to coordinate the cooperation process of students' mathematical modeling, how to improve their comprehensive ability of mathematical modeling, we will state several suggestions on the teaching and training of mathematical modeling course:

(1) Division of teaching, improvement the quality of teachers and students.

To cultivate all-round developed high-quality talents in higher education, there must have a high-quality teaching team. However, the overall quality of the students and teachers in our university is not high, which has restricted the development of mathematical modeling course. Grasping the knowledge and techniques of the mathematical modeling course is a big challenge to the both teachers and students. We work out the education program, so, each of teachers in our team has a relevant subject teaching based on his major. The relevant knowledge of mathematical modeling is regularly discussed in our team. In addition, as the trips have become more common, our team can learn about the good teaching experience of other universities, and be an experienced team with significant skills. For example, Xiaohai Qu, having received his Ph.D. from the National University of Defense Technology, based on his personal experience at this university, he come out with some thought-provoking ideas about the teaching of the course.

(2) Renewal teaching ideas, enrich contents of the course and reform teaching methods.

Converting the learning mode of students is to enhance the theoretical explanation of learning mode, to change teaching and education concepts of teachers, and to improve the quality and ability of teachers and students. We have made multimedia courseware according to the teaching contents, which can be shared and adapted in our team.

(a) research-oriented teaching model with traditional teaching

This change comes from the reflection of teaching method and content as follows: First, Chinese traditional math education would be regarded that is good at training mathematics knowledge and skill. Higher education presupposes the proper use of mathematics if necessary. But, there is a few case to use mathematics in the society and if the case occurred, skills and knowledge is not enough. In the everyday life, what is more important is thinking. Second, higher education cannot connect various knowledge and skills learned in university. We have to make an environment to summing up known knowledge rather than many pieces of knowledge. Third, the content of mathematics is not attractive. To achieve a good teaching organization, it is necessary to conduct the delaminating teaching according to students' knowledge structure and level of intelligence, strengthen the cultivation of students' ability of using computers and the relevant instructional software, give elaborate exposition of typical cases and enhance the training of students' capability of practical application. The course is based on applications of computers in the traditional mathematical modeling course tries to integrate the problem-solving methods. Researchoriented teaching model was a teaching system which integrated study and research. By researchoriented teaching, the students must base on their own initiative, instead of studying passively. So, converting the learning mode of students is to enhance the theoretical explanation of learning mode, to change teaching and education concept of teachers, and to improve the quality and ability of teachers and students. Key to this model is the notion that mathematical knowledge for teaching involves developing coherent understandings that enable teachers to see a variety of mathematical ideas as conceptually and structurally related. While teachers are often aware of particular examples that employ a particular mathematical structure, they are often unaware of the benefits of connecting the special cases and focusing their (and their students') attention on the larger mathematical concept involved.

(b) The establishment and implementation of the online learning platform.

The characteristics of network learning.

Network learning refers to the learning activity through the computer network, the main form of autonomous learning, negotiated learning, personalized learning, interactive and cooperative learning and social learning. It has three main characteristics: first, the network can share rich learning resources; second, independent learning and collaborative learning are mainly learning form; Third, Network learning changes the model of learning, and provides educational 
opportunities for more people. According to their own learning plan and the needs, so the network learning platform is the best solution of mathematical modeling course after-school learning.

The key of establishing the online learning platform.

First, we make the network courseware with clear teaching aim, strong interesting, high interactivity; Second, according to CUMCM, we divide the contents into small practical parts, and upload sufficient database resources by the backstage management system, which make students freely to choose their interest topic. Moreover, we hold virtual mathematical modeling contest for students. It makes the students from the different departments and subjects study each other, and promotes the combination among different subjects; Third, the online learning platform is set up based on teachers play leading role. Experiment teaching system provide the terrace of better study and master knowledge for students, and the study and exchange of students and teachers are convenient by way of the network. Computers are a window to the net worked world of information and knowledge, thus, we build QQ group of mathematical modeling and Blog, and so on. Fourth, we design the learning evaluation system, and give each student a fair evaluation for the solutions.

(c) The reform of the teaching contents and the system according to the Education and major purpose.

Mathematical modeling course has the distinguishing feature that: (a) there are too many knowledge such as Calculus, Algebra and Geometry, Random mathematics, Numerical computing, Optimization and Statistics for students to grasp. (b) there are some mathematical software as experimental tools in the course. As we have mentioned, in China, mathematical modeling course is the last one of the mathematical courses for undergraduate students of non-mathematical majors. When students finish these courses, they may have no chance to learn more mathematical courses before they graduate. Therefore, we think it is important for the students to learn some mathematics most commonly used in practice. It is not strange that one may argue that too many mathematical contents can be included, since almost all mathematics could be applicable. We think it is crucial for the undergraduate students with non-mathematical majors to know the basic concepts and techniques in these fields, which are usually only taught to mathematics students before. Therefore, we position the course on teaching and learning applied mathematics by the means of mathematical modeling with mathematical software. But at Hunan University of Arts and Science, the Mathematical modeling course has only 48 lectures with each consisting of 45 minutes, thus we should select the course contents very carefully. Linear/nonlinear programming, statistics, computer simulation, numerical computing are important contents, and MATLAB and LINGO are experimental tools in the course, which are mathematical software products from The MathWorks and LINDO Systems, respectively.

(3) Combining the voluntary principle with advantage complementary in CUMCM.

Grouping experimental teaching is a quite important step during the whole teaching process. According to the total score of students, we divide the students into three class A, B, C: A is a top student, $\mathrm{B}$ is a secondary student, $\mathrm{C}$ is the poor academic performance, learning enthusiasm and self-confidence student. Three people (A, B, C each one)from different specialties make a group. To complete the experimental task, the teachers encourage everyone in the group to cooperate, colead, and co-create.

It is well known that three people make up a team, and complete the contest in three days in CUMCM. Through the powerful combination of complementary advantages, enhance the overall competitiveness of the three sides. However, the principle of voluntariness shall be practiced. We should respect their choice and individuality, encouraging them to pursue their true passions.

(4) The strong supports and active cooperation from the competent authorities.

To improve the quality of teachers, competent authorities support for teacher training, attending the meetings and research funding on mathematical modeling course.; To stimulate the students' interest in learning mathematical modeling course, our university provides advanced laboratory, and work out favorable policies for students. In addition, our university provides adequate funding support for CUMCM, and work out awarding measures for teachers and students. 


\section{Responses from students}

In 2012, we conducted a questionnaire survey in the students enrolled in the course. 172 responses were received, and the analysis revealed that the course is very successful in the sense that the students like the course very much and they also show great interests to learn more mathematics. Some of the results from the survey are listed in below.

(a) Has the course achieved its objective? Yes (93\%) No (7\%)

(b) Is the content of the course appropriate? Yes $(90 \%)$ No (10\%)

(c) Do you think the course is helpful to you? Yes (96\%) No (4\%)

(d) How you do think about the difficulty of the course? Proper (48\%) Too difficult (50\%) Too easy (0\%)

No answer (2\%)

(e) How you do think about the burden of the assignments? Proper (70\%) Too many (23\%) Too little (5\%)

No answer (2\%)

(f) How you do think about the teaching methods used in the class?

Good (73\%) Not good (9\%) No answer (18\%)

\section{Conclusions}

In this paper, we have shared our experiences in teaching and training of the mathematical modeling course at Hunan University of Arts and Science. The objective of the course is to teach students to learn applied mathematics (in particular, numerical computing, optimization and statistics) by the means of mathematical modeling and mathematical software. Although we are trying to integrate mathematical modeling, mathematical software, numerical analysis, optimization and statistics into a single course of mathematical experiments, we also realize that this work is difficult. We should not simply mix these traditional courses together, or just treat the course as a mathematical software course. Furthermore, as modern mathematics is changing from time to time, it is challenging to revise and redesign the course to reflect the advances in mathematics and mathematical software.

\section{Acknowledgments}

This work is partially supported by the Teaching Reform Foundation of Hunan province ordinary university ([2012],142, [2013],351), Hunan province college students' research learning and innovative experiment project(2013).

\section{References}

[1] S. Xiao: Research report on reforms of higher mathematics for non-mathematical specialties". Beijing: Higher Education Press., 2000.

[2] S. Xiao:Reforms of the university mathematics education for non-mathematical specialties”. In T. Li (Ed.), Proceedings of the International Congress of Mathematicians, Vol. III, p. 897-906. Beijing: Higher Education Press., 2002.

[3] J. XiE: Thirty years of mathematical modeling courses, A review and reflection. Mathematical Modeling and its Applications, Vol. 1(2012), p.48-52.

[4] J. Borwein, D. Bailey :Mathematics by experiment, Plausible reasoning in the 21st century. Natick, MA: A. K. Peters.,2003.

[5] J. Borwein, D. Bailey : Experimentation in mathematics: Computational paths to discovery, Natick, MA: A. K. Peters.,2004 
[6] T. Lingefjärd :Mathematical modeling for preserve teachers: A problem from anesthesiology, The International Journal of Computers for Mathematical Learning , Vol. 7(2004), p. 117-143.

[7] Q. Jiang: From mathematical modeling to mathematical experiments. In J. F. Matos, W. Blum, K. Houston, \& S. P. Carreira (Eds.), Modeling and Mathematics Education: ICTYMA Applications in Science and technology, Chichester: Horwood, 2001.

[8] S. Li, F. Chen: Mathematics experiments. Singapore, World Scientific.,2001. 